\title{
Recycling and Management of Waste at Source (Home)
}

\author{
Tej Kumar Nepal \\ Student, School of Ecology and Environment Studies, Nalanda University, Rajgir, Bihar, India \\ Email: tejkumarnepa197@gmail.com
}

\begin{abstract}
Solid waste management is a global issue that affects every individual living in the world directly or indirectly. Failing to manage the waste properly will cause harm on public health, our natural environment, and even our happiness and prosperity. When asked about the reason behind the failure of third time plastic ban in Bhutan, one of the Bhutanese said it's because of the lack of cooperation from public to support the move of government. Clean Bhutan, a non-governmental organization (NGO) that aims Zero Waste Bhutan by 2030, has collected around 5,900 metric tons of waste from December 2014 to February 2018. This project will create some awareness regarding the management of waste at individual level when people come in contact with the family of the researcher. It also talks abot how waste management and biodiversity conservation can go side by side.
\end{abstract}

Keywords: Waste, environment, reuse, recycle, product

\section{Introductory Statement}

Waste can be defined as the unwanted thing or a substance that no longer serves its purpose [21]. The generation of solid waste is increasing with increase in population. The need to feed, provide shelter and to cloth the increasing population generates huge quantity of waste which makes it difficult to manage the solid waste [12]. Solid waste management is a global issue that affects every individual living in the world directly or indirectly [34]. Failing to manage the waste properly will cause harm on public health, our natural environment, and even our happiness and prosperity [31]. Pollution and waste are a kind of issue that needs to be addressed from the source itself [25], and to achieve this collaboration among government, public sector, community and individual ought to be strong [13]. If individual person are responsible about the things they consume, alter the choices, shift to more eco-friendly consumption and monitor the waste and if possible segregate the waste and reuse it, then zero waste can be achieved [7]. There are two ways to educate the citizens about the importance of waste management at individual level: the first way is through inclusion of waste segregation and management into religious discourses [14]. His Holiness the Je Khenpo (Chief Abbot of Bhutan) announced the importance of managing the waste at individual level in most of the discourses and it proved effective as many elders followed it [5] [4]. The other way is to include waste management strategy into syllabus and educate and brainstorm the young minds about the importance of waste management [16] [17] [1].

Dorokha is under Samtse Dzongkhag, located in southern part of Bhutan. The inhabitants are mostly Hindu. The small cluster of shops falls in town development and the locals say that with development, the waste generation is increasing. The local fear that the waste would be difficult to manage once the town development is completed. People of Dorokha mostly produces waste like plastic carry bags, discarded metals, tins, containers, plastic bottle (oil and water), junk wrappers, used stationary products, clothes and organic waste. When asked about the reason behind the failure of third time plastic ban, one of the local said it's because of the lack of cooperation from public to support the move of government. With community getting connected with road and electricity, the air pollution has decreased drastically but the quantity of waste produced is increasing rapidly. People are in harmony with nature but they are not concerned with the ways to manage the waste at individual level. This is because due to the lack of knowledge and lack of waste management equipment.

\section{Background}

The world generates around 2 billion tons of municipal solid waste every year, and if the world doesn't take urgent action the generation of municipal solid waste will increase by three quarters to 3.4 billion tons by next 30 years [31]. Most of the waste generated by rich countries either land up in poor countries or in water body severly effecting the diversity of marine and land ecosystem [8]. Some of the waste generated around the world are: liquid waste, generated by household and industries; municipal solid waste, generated by households, schools, office, hotels and other institution; industrial 
waste, generated by industries that has toxicity; agriculture waste and residues; and hazardous waste, generated by every sectors [20]. The countries that produces huge quantity of waste are Kuwait, Antigua and Barbuda, St. Kitts and Nevis, Guyana, and Sri Lanka [27]. If the world doesn't work urgently for the management of the waste, the planet may loose its rich diversity of flora and fauna to waste [11] [30]. The governmant of the nations should work together to combat the prevailing issue of waste generated from international trade.

Bhutan has championed the conservation of biodiversity before she joined any of the international conventions and bodies [28] [6]. Bhutan is experiencing the climate change and globalization, and it is obvious that the generation of different type of waste is increasing yearly [29]. Bhutan is the only country that is cartbon negative (absorbs more carbon dioxide than it emits) [19] [32], but glaciers in Bhutan are melting because the global temperature is increasing [33]. There are laws and policies in place to regulate and coordinate the management of waste, but it doesn't prove effective. The plastic ban policy failed for three times. All the hardwork of the government and associated agencies went in vain. This issues proves how serious we are regarding the management of waste. Management of waste is becoming an issue in Bhutan [22]. Bhutan produces around 861 metric tons of waste every week [10]. If the data shows that the waste generation has increased over years, it means that people are not able to manage the waste properly. Clean Bhutan, a non-governmental organization that aims Zero Waste Bhutan by 2030 [9], has collected around 5,900 metric tons of waste from December 2014 to February 2018. Are we only able to champion the environmental conservation? Bhutan categories waste into 5: non-hazardous waste; hazardous waste; medical waste; e-waste; and other waste (industrial waste, municipal waste and agricultural waste) [23]. The Royal Governemnt of Bhutan is working closely with all the associated agencies and bodies to prevent and reduce the volume of waste generation, promote segregation, reuse, rescycling, and manage the waste in an environmentally sound manner. Lot of initiatives and activities are carried out to become zero waste by 2030 . The country encourage waste management entrepreneurship in prevention, collection, segregation and recycling of waste [24]. The Waste Prevention and Management Regulation 2016 suggests avoiding, eliminating or substituting, reducing, reusing, recycling, recovering, treating and disposing the waste properly.
Most of the waste that are generated can be reused or recycled [26]. A thing or and item may be waste for an individual but it can become resourcce for another individual [18]. Most household reuses the soft drink bottles to store water, unwanted tires to make flower pots, junk wrappers to make decorative items and to grow flora saplings, old clothes are either donated or used to make scare crow [15]. Change always begins from home. People can avoid the use of some materials, segregate the waste, adopt composition and reuse the material [2]. Re-purposing household waste is a good way to reduce volume of waste [3]. The waste that ends up in water body effects the marine life severly. The waste management by people of Dorokha are very poor as they either dump the waste or they burn the waste, causing advese affect to the environment. This project will create some awareness regarding the management of waste at individual level when they come in contact with the family of the researchers. No previous study of similar kind was carried out in Dorokha.

\subsection{Aim}

Turning waste (junk wrapper and plastic bottles) into resources.

\subsection{Objectives}

- Reduce waste disposal at home

- Protection of environment through waste management techniques

- Practice reduce and reuse of waste

- Beautification of home and surrounding to encourage and inspire the locals

\section{Methodology}

\subsection{Site Selection}

No technique or comfort was seen while site selection because of the ongoing pandemic, COVID19. Home (Ngagang, Dophuchen, Dorokha, Samtse, Bhutan) was selected as the site for the project.

$\begin{array}{ll}\text { 3.2. Materials required for } & \begin{array}{c}\text { for } \\ \text { collecting and segregating }\end{array} \\ \text { the } \\ \checkmark & \text { Sack to store the collected items } \\ \checkmark & \text { Waste (plastic bottle and junk wrappers) } \\ \checkmark & \text { Book } \\ \checkmark & \text { Pencil or pen } \\ \checkmark & \text { Gloves }\end{array}$




\subsection{Collection of waste}

The plastic bottles and junk wrappers were collected over a period of 45 days (April $10^{\text {th }}, 2020$ to May $\left.25^{\text {th }}, 2020\right)$. The junk wrappers collected from home were not sufficient for the project, therefore a shop in a walking distance was asked for help and around $50 \%$ of junk wrappers were collected from the shop.

\subsubsection{Collection of junk wrappers}

The junk wrappers were collected from two sites, from home and shop. Measuring the weight of the waste was not possible as it was hard to get a weighing balance. Only vegetable shops possessed a weighing balance and the shopkeepers were reluctant to provide the service fearing the ongoing pandemic. Plastic wrappers of chewing gum, noodles, chips, labels on bottles, carry bags, biscuits and book covers were collected. The junk wrappers were used to make mat to sit.

\subsubsection{Collection of plastic bottles}

The bottles were kept from the home. Measuring the weight was not possible as it was uncomfortable to carry waste and go in search of weighing balance. Plastic bottles from fruit juice, carbonated drinks, mineral water and oil were collected. The plastic bottles were used to make water sprinkler and bird feeder.

$\begin{array}{ll}\text { 3.4. Materials required in } \\ \text { converting waste into new product } \\ \checkmark & \text { Plastic bottles } \\ \checkmark & \text { Junk wrappers } \\ \checkmark & \text { Scissors } \\ \checkmark & \text { Glue or tape } \\ \checkmark & \text { Ruler } \\ \checkmark & \text { Pen or pencil } \\ \checkmark & \text { Thread } \\ \checkmark & \text { Sharp tool or nail }\end{array}$

\subsection{Procedure in product creation}

The collected waste was used in creating three different products: water sprinkler from plastic bottle, bird feeder from plastic bottle and mat from wrappers. The procedure for individual are mentioned below.

\subsubsection{Water sprinkler from plastic bottle}

$\therefore \quad$ Poked holes in scatter pattern (or whatever designed required based on the interest) in
1.5 liter plastic bottle with a sharp tool or nail.

$\therefore \quad$ Connected the opening of the bottle with the end of water pipe. We can either permanently connect the two end together by melting a bit of plastic or can connect it temporarily with cloth pieces.

$\therefore \quad$ It is ready to put into use. Turn on the tap and wait for the pressure to build up.

$\therefore \quad$ The water sprays like from a real sprinkler.

\subsubsection{Bird feeder from plastic bottle}

$\therefore \quad$ Cleaned and dried the water bottle to avoid the contamination and wetting of the bird seed or rice.

$\therefore \quad$ Made a window in the bottle for birds to eat the seed. The window was made in middle of the bottle: 2 inches were kept in base for keeping the seed or rice; the window frame is $10 \mathrm{~cm}$ by $7 \mathrm{~cm}$.

$\therefore$ Inserted some sticks to allow bird to hold-on while eating the seed or rice.

$\therefore \quad$ Tied a wire to the neck of the bottle to hand the bird feeder from a height.

\subsubsection{Plastic mat from plastic wrappers}

$\therefore$ The collected wrappers were washed and kept to dry. The plastic were washed because to clean anything that was sticking to the plastics.

$\therefore \quad$ The plastics were cut in long shape to make it easy to use while weaving in into design.

$\therefore \quad$ The plastic were woven into design in 25 days.

Creation of product at home is easy, cheaper and the creator can use his/her creative idea to design the product. The disadvantage of such method is that it will not long last, can get damaged by wind and water, and can pose threat to environment if not managed properly.

\section{Result and discussion}

Most of the people who deal with waste and those that are involved in management of waste tend to define waste as a wrong substance at a wrong place in a wrong form at a wrong time. Not all the waste that is discarded is waste because it turns out to be raw material for some products. The project at individual level made us realize how people throw away the resources. Some of the products made from waste are listed below: 


\subsection{Water sprinkler}
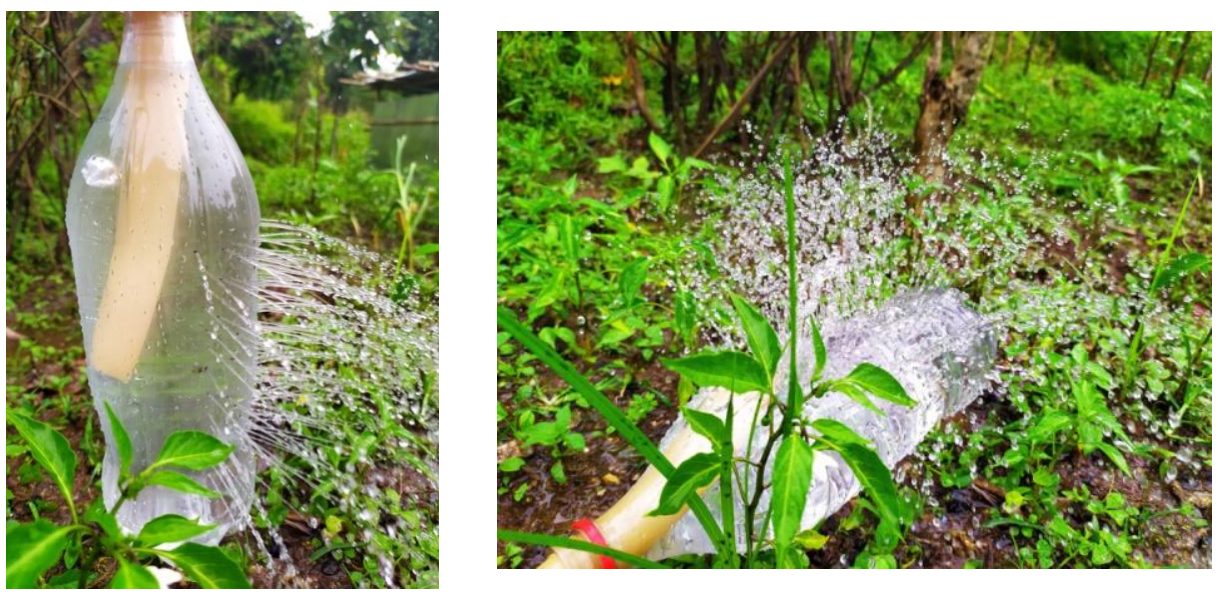

Figure 1: Water sprinkler made from carbonated drink bottle

The water sprinkler can be made from any type of plastic beverage container. This activity is not only teaches waste management techniques but it also prevent from waste getting dumped in environment. The product proved that it works more smoothly and in an easy way than those bought from the store and shops. It is easy to make, saves money and it is ecofriendly. The sprinkler with small hole is saplingfriendly as it causes very less damage to them. Recommended activity with kids as individual can try to make shower during summer days.
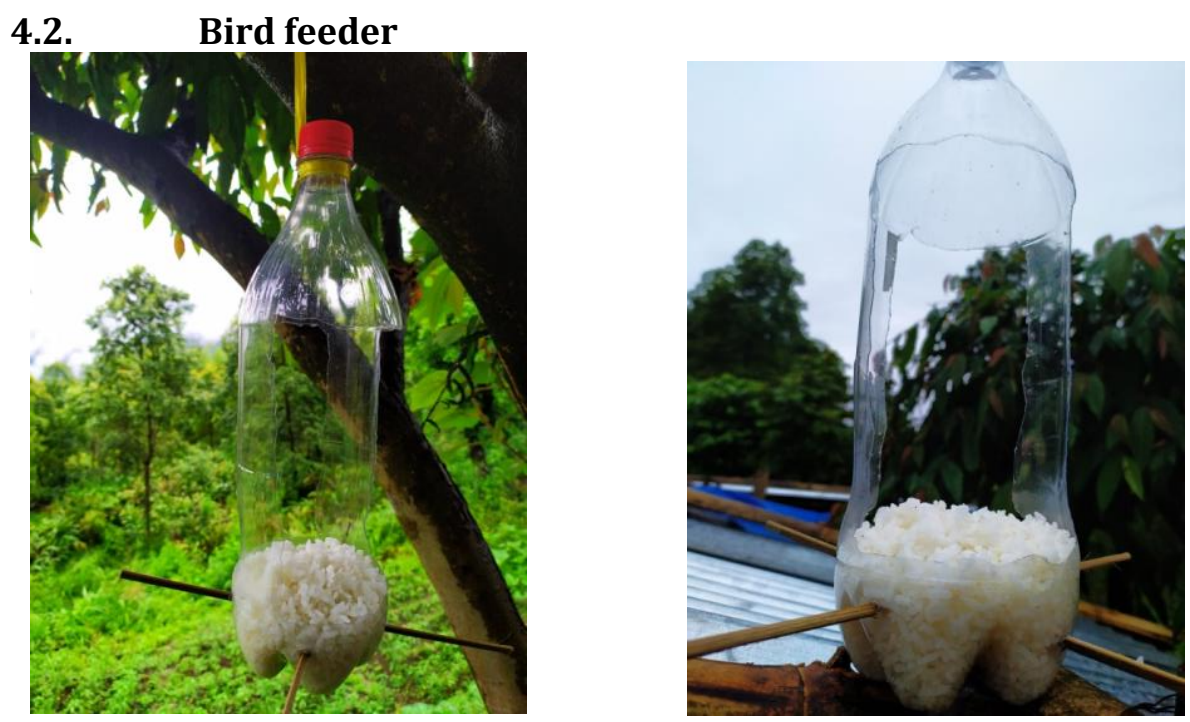

Figure 2: Bird Feeder made from carbonated drink bottle

This activity is mostly tried in creative ways by birders around the globe. It is easy to make and it can attract diverse species of birds during sunny days. It is cheap to make and it is eco-friendly. Anyone who makes and hangs the bird feeder needs to change the water regularly and refill seed when it is finished.
The only disadvantage it got is that it cannot support large birds. Around 5 bird feeders were made and placed in different location where bird movements were at maximum. The birds I have seen eating from bird feeder are Common Myna (Acridotheres tristis), Rock Pigeon (Columba livia), Scarlet Minivet 
(Pericrocotus speciosus), Black Drongo (Dicrurus macrocercus), Red-vented Bulbul (Pycnonotus cafer), Black Bulbul (Hypsipetes leucocephalus) and
House Sparrow (Passer domesticus). Biodiversity conservation and waste management goes hand in hand.

\subsection{Plastic Mat}
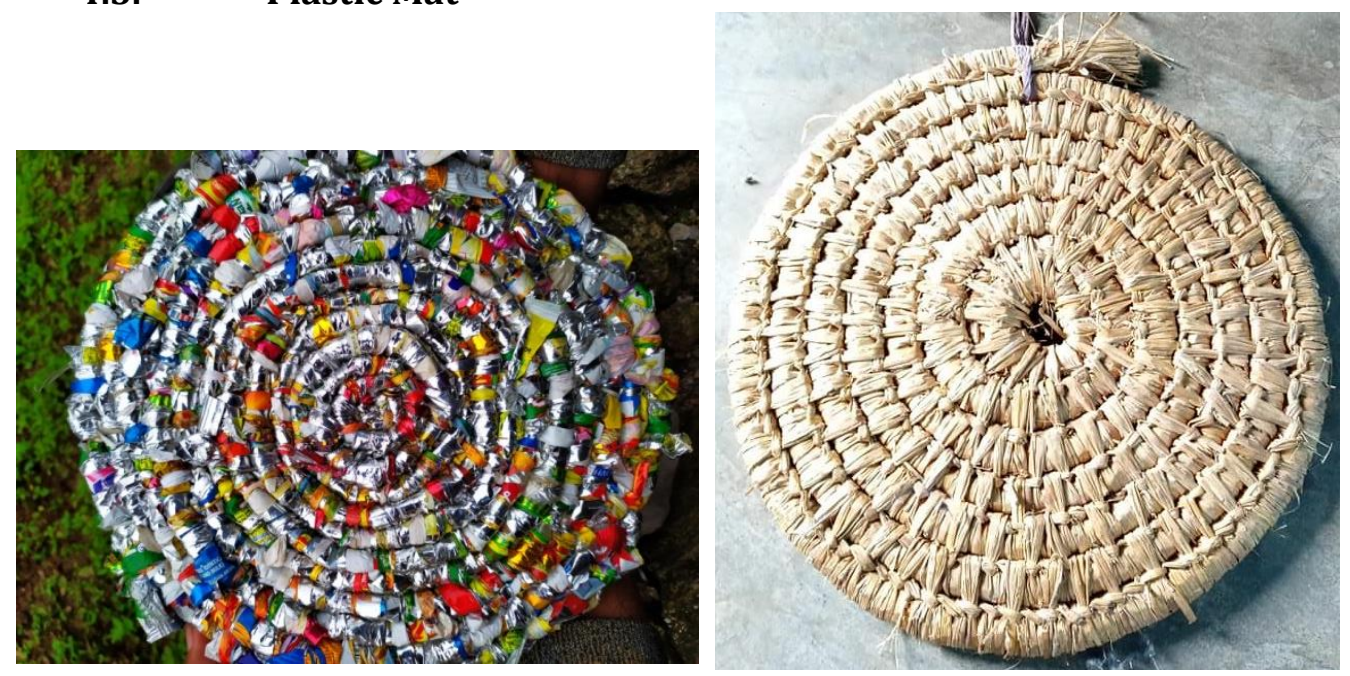

Figure 3: The shiny and the colorful mat is made from plastics and the other mat is made from straw

The making of plastic mat is very creative way to use huge amount of plastic waste. Most of the people residing in Dorokha and other southern part of Bhutan makes mat from straw and it is quite warm compared to those made from cloth. The actual credit for the idea goes to the Lhotshampa style mat. This helps reduce plastic waste from getting dumped in Environment.

Creating new product from waste helps in reducing waste dumped in landfill and it also reduces the impact on environment and biodiversity. The objective to reduce waste at home, protect environment through waste management strategy, practice reduce and reuse, and beautification were mostly met. The species of birds were also benefitted from the project. Some of the recommended activities to carry out to reduce waste at home are: dustbin fro plastic bottle; recreational park with different waste; flower pots from bottles; sign board from caps and mini greenhouse.

\section{Conclusion}

Population growth, industrial growth and urbanization had lee to waste management problems around the world. The world cannot stop to produce the waste instantly, but it can reduce, reuse and recycle the waste at the source. The creative ways to manage waste are very simple and affordable. The most of the waste that goes from the household will reduce drastically if everyone has the knowledge of waste management. With rise in literacy rate of every nation the waste generation is also increasing, does educating the young mind going in vain? There are numerous ways to management waste at the source, but still there is rise in waste dumped at landfill. The waste management will become successful when people manage and segregate at individual level, help government in implementing rules and regulations regarding the same and creating awareness among those people lacking waste management knowledge. Working together towards a similar goal will help achieve the goal. Care for environment should come from wisdom, not knowledge.

\section{References}

[1]. Abdul-Wahab, S. A., Abdulraheem, M. Y., \& Hutchinson, M. (2003). The Need for Inclusion of Environmental Education in Undergraduate Engineering Curricula. International Journal of Sustainability in Higher Education, 4(2), 126137.

[2]. Abella, T. A. (2013). Follow the Rs: Reduce, Replace, Reuse, Recycle, Recover, Refuse and Reject, Rethink. Envirocities eMagazine.

[3]. Agarwal, R., Chaudhary, M., \& Singh, J. (2015). Waste Management Initiatives in Indai fro Human Well Being. European Scientific Journal, 105-127.

[4]. Allison, E. (2014). Waste and Worldviews: Garbage and Pollution Challenges in Bhutan. 
Journal for the Study of Religion, Nature and Culture, 8(4), 405-428.

[5]. Allison, E. (2019). The Reincarnation of Waste: A CAse Study of Spiritual Ecology Activism for Household Solid Waste Management: The Samdrup Jongkhar Initiative of Rural Bhutan. Religions, 10(9), 514.

[6]. Banerjee, A., \& Bandopadhyay, R. (2016). Biodiversity Hotspot of Bhutan and its Sustainability. Current Science, 110(4), 521-527.

[7]. Barr, S., Ford, N. J., \& Gilg, A. W. (2003). Attitudes Towards Recycling Household Waste in Exeter, Devon: Quantitative and Qualitative Approaches. Local Environment, 8(4), 407-421.

[8]. Berglund, C., \& Soderholm, P. (2003). An Econometric Analysis of Global Waste Paper Recovery and Utilization. Environmental and Resource Economics, 26(3), 429-456.

[9]. CleanBhutan. (2014, February 2014). Vision. Retrieved from Clean Bhutan: https://cleanbhutan.org/?page_id=57

[10].Dorji, J. (2021). Rubber Slippers and Environmental Effect in KCB School in Bhutan. South Asian Journal of Social Studies and Economics, 9(1), 18-25.

[11].Essl, F., Dullinger, S., Rabitsch, W., Hulme, P. E., Pysek, P., Wilson, J. R., et al. (2015). Delayed Biodiversity Change: No Time to Waste. Trends in Ecology and Evolution, 30(7), 375-378.

[12].GoI. (2019). Plastic Waste Management: Issues, Solutions \& Case Studies. New Delhi: Ministry of Housing \& Urban Affairs.

[13].Herat, S., \& Agamuthu, P. (2012). E-waste: A Problem or an Opportunity? Review of Issues, Challenges and Solutions in Asian Countries. Waste Management and Research, 30(11), 11131129.

[14].Intahphuak, S., Narog Pamala, B. Y., \& Buakhiao, A. (2017). Religion Role on Community Movement for Solid Waste Management. The Journal of Solid Waste Technology and Management, 43(4), 321-327.

[15].Jibril, J. D., Sipan, I. B., Sapri, M., Shika, S. A., Isa, M., \& Abdullah, S. (2012). 3Rs Critical Success Factor in Solid Waste Management System for Higher Educational Institutions. Procedia-Social and Behavioral Sciences, 65, 626-631.

[16].Karatas, A., \& Karatas, E. (2016). Environmental Education as a Solution Tool for the Prevention of Water Pollution. Survey in Fisheries Science, 3(1), 61-70.

[17].Kortland, K. (1996). An STS Case Study About Students' Decision Making on the Waste Managemnt. Science Education, 80(6), 673-689.

[18].Memon, M. A. (2010). Integrated Solid Waste MAnagement Based on the 3R Approach.
Journal of Material Cycles and Waste Management, 12(1), 30-40.

[19].Munawar, S. (2016). Bhutan Improves Economic Development as a Net Carbon Sink. The CLimate Institute.

[20]. Nowakowski, P., \& Pamula, T. (2020). Application of Deep Learning Object Classifierto Improve e-waste Collection Planning. Waste Management, 109, 1-.

[21]. Omela, F. K., \& Alakinde, M. K. (2013). Managing the Unwanted Materials: The Agony of Solid Waste Mangement in Ibadan Metropolises, Nigeria. International Journal of Education and Research, 1(4), 12.

[22].Phuntsho, S., Dulal, I., Yangden, D., Tenzin, U. M., Herat, S., Shon, H., et al. (2010). Studying Municipal Solid Waste Generation and Composition in the Urban Areas in Bhutan. Waste Management and Research, 28(6), 545551.

[23].RGoB. (2009). Waste Prevention and Management Act 2009. Thimphu: Royal Government of Bhutan.

[24].RGoB. (2016). Waste Prevention and Management (Amendment) Regulation 2016. Thimphu: Royal Government of Bhutan.

[25].Rhodes, C. J. (2018). Plastic Pollution and Potential Solutions. Science Progress, 101(3), 207-260.

[26].Sakai, S.-i., Yoshida, H., Hirai, Y., Asari, M., Takigami, H., Takahashi, S., et al. (2011). International Comperative Study of $3 \mathrm{R}$ and Waste Management Policy Developments. Journal of Material Cycles and Waste Management, 13(2), 86-102.

[27].Sebastian, A. (2019, November 02). Markets Economy. Retrieved from Investopedia: https://www.investopedia.com/articles/marketseconomy/090716/5-countries-produce-mostwaste.asp

[28]. Tempa, T., Hebblewhite, M., Mills, L. S., Wangchuk, T. R., Norbu, N., Wangchuk, T., et al. (2013). Royal Manas National Park, Bhutan: A Hot Spot for Wild Fields. Oryx, 47(2), 207210

[29].Tshomo, U., Dorji, C., \& Dahal, Y. (2020). Integrated Waste Management in Bhutan. Circular Economy: Global Perspective, 67-86.

[30].Vanapalli, K. R., Sharma, H. B., Ranjan, V. P., Samal, B., Jayanta Bhattacharya, B. K., \& Goel, S. (2021). Challenges and Strategies for Effective Plastic Waste Management During and Post COVID-19 Pandemic. Science of the Total Environment, 750, 141514.

[31].Vasquez, E. I., Wahba, S., \& Kaza, S. (2018, September 20). Sustainable Cities. Retrieved from World Bank: 
https://blogs.worldbank.org/sustainablecities/here -s-what-everyone-should-know-about-waste

[32]. Yangka, D., Rauland, V., \& Newman, P. (2019).

Carbon Neutral Policy in Action: The Case of Bhutan. Climate Policy, 19(6), 672-687.

[33].Youn, S. (2017, October 17). Travel. Retrieved from National Geographic: https://www.nationalgeographic.com/travel/desti nations/asia/bhutan/carbon-negative-countrysustainability/

[34].Zhao, W., Voet, E. V., Zhang, Y., \& Huppes, G. (2009). Life Cycle Assessment of Municipal Solid Waste Management with Regard to Greenhouse Gas Emissions: Case Study of Tianjin, China. Science of the Total Environment, 407(5), 1517-1526. 